\title{
Erratum to: Student perception of assessment practices: towards 'no loser' classrooms for all students in the ethnic minority schools in Hong Kong
}

\author{
Ming-Tak Hue ${ }^{1}$ • Chi-Hung Leung ${ }^{1}$ • \\ Kerry John Kennedy ${ }^{2}$
}

\section{Erratum to: Educ Asse Eval Acc \\ DOI 10.1007/s11092-014-9205-2}

The author group in the original version of this article contained mistake. The third author should be Kerry John Kennedy, instead of Kerry Johon Kennedy. The correct name now appears above.

Ming-Tak Hue mthue@ied.edu.hk

Chi-Hung Leung chhleung@ied.edu.hk

Kerry John Kennedy kerryk@ied.edu.hk

1 Department of Special Education and Counselling, The Hong Kong Institute of Education, Hong Kong, China

2 Department of Curriculum and Instruction, The Hong Kong Institute of Education, Hong Kong, China 